\title{
ESTIMASI ALIRAN SUNGAI BAWAH TANAH DI DAERAH DENGOK DAN NGREJOK WETAN GUNUNG KIDUL, MENGGUNAKAN METODE VLF-EM DAN VLF-EM-VGRAD
}

\author{
Febria Anita, Purwantiningsih \\ Jurusan Fisika, Universitas Nasional Jakarta \\ Jl. Sawo Manila, Pejaten Ps. Minggu Jakarta \\ Email:1ya_2802@yahoo.co.id,purwanti.ningsih85@yahoo.co.id
}

\begin{abstract}
A baseline river flow estimation has been conducted in the area of Duncok and Ngrejok Wetan Gunung Kidul, using VLF-EM and VLF-EM-VGRAD methods to find out VLF response of tilt angle mode. Interpretation is done from VLF and VLF-EM-VGRAD data of tilt angle and ellipticity to estimate underground stream that is interpreted qualitatively and quantitatively. Measurements were made on July 22-26, 2014. The data were processed by using uses MATLAB R2014a computational language. This qualitative interpretation is done by processing data filtered by Moving Average through Karous-Hajelt filter and Fraser filter so as to show the anomaly of underground conductive object. Of the two methods used, the most effective method is with VLF EM, it can be seen from the result of the Karous Hjelt filter shows the contrast resistivity in VLF EM compared to VLF-EM-Vgrad
\end{abstract}

Key words: VLF-EM response, VLF-EM-VGRAD, tilt angle mode, Karous-Hajelt filter

\section{PENDAHULUAN}

Morfologi karst Gunungsewu yang terletak di wilayah Gunungkidul merupakan kawasan perbukitan batu gamping (limestone) dengan bentangan alam karst yang tandus dan kekurangan air permukaan. Proses geologi pada kawasan karst ini terbentuk pada batuan karbonat yang mudah bereaksi dan larut dalam air, terutama air yang bersifat asam. Batuan karbonat berpotensial menghasilkan airtanah karena porositas sekunder hasil pelarutan akan membentuk rongga dengan diameter yang cukup besar sehingga air di atas permukaan akan mudah lolos ke bawah permukaan dan mengalirkan air dalam volume yang besar (Kusumayudha, 2005). Air yang mengalir di bawah permukaan akan membentuk suatu pola aliran tertentu seperti sungai permukaan dengan melewati lorong-lorong gua yang dikenal sebagai aliran sungai bawah tanah.
Untuk mengetahui jalur sungai bawah tanah yang melewati lorong-lorong goa tersebut diperlukan suatu metode geofisika yang efektif dan efisien sesuai dengan keadaan topografi di daerah Gunungsewu. Metode tersebut diharapkan dapat membantu melaksanakan pemetaan regional potensi sungai bawah tanah di kawasan karst. Sismanto dkk. (2003) pernah melakukan uji coba di sekitar Gua Bribin dengan metode VLF dan dihasilkan respon yang jelas dan akuisisi data yang relatif lebih mudah walaupun medan cukup berat, sehingga metode elektromagnetik VLF ini cukup menjanjikan untuk digunakan dalam pemetaan sungai bawah tanah seperti di daerah Gunungkidul Yogyakarta ini.

\section{DASAR TEORI VLF-EM}

Persamaan Maxwell merupakan bentuk dari gelombang elektromagnetik yang 
berhubungan dengan vektor medan listrik dan medan magnet adalah:

$$
\begin{aligned}
& \nabla \times \bar{E}=-\frac{\partial \bar{B}}{\partial t} \\
& \nabla \times \bar{H}=\bar{J}+\frac{\partial \bar{D}}{\partial t}
\end{aligned}
$$

Dengan $\bar{l}=$ rapat arus listrik $\left(\mathrm{A} / \mathrm{m}^{2}\right), \bar{E}=$ medan listrik $(\mathrm{V} / \mathrm{m}), \bar{B}=$ induksi magnetik $\left(\mathrm{Wb} / \mathrm{m}^{2}\right), \bar{D}=$ pergeseran listrik $\left(\mathrm{C} / \mathrm{m}^{2}\right)$ dan $\bar{H}=$ medan magnetik $(\mathrm{A} / \mathrm{m})$. Apabila diasumsikan medan $\bar{E}$ dan $\bar{H}$ tersebut sebagai fungsi waktu eksponensial, maka akan diperoleh persamaan vektorial sebagai berikut ;

$$
\begin{aligned}
& \nabla^{2} \bar{E}=i \omega \mu \sigma \bar{E}-\omega^{2} \varepsilon \mu \bar{E} \\
& \nabla^{2} \bar{H}=i \omega \mu \sigma \bar{H}-\omega^{2} \varepsilon \mu \bar{H}
\end{aligned}
$$

Dimana ${ }^{\sigma}$ konduktifitas listrik (mho/m), $\mu$ permeabilitas $(\mathrm{H} / \mathrm{m})$ dan $\varepsilon$ permitivitas dielektrik (F/m). Pada persamaan (2.3) dan (2.4) bagian kiri pada sisi kanan menunjukkan arus konduksi dan bagian kanannya menunjukkan sumbangan arus pergeseran.

Medan elektromagnetik primer sebuah pemancar radio, memiliki komponen medan listrik vertikal $\mathrm{Ez}$ dan komponen medan magnetik horizontal Hy tegak lurus terhadap arah perambatan sumbu $\mathrm{x}$. Pada jarak yang cukup jauh dari antena pemancar, komponen medan eletromagnetik primer $\mathrm{Hy}$ dapat dianggap sebagai gelombang yang berjalan secara horizontal. Jika di bawah permukaan terdapat suatu medium yang konduktif, maka komponen medan magnetik dari gelombang elektromagentik primer akan menginduksi medium tersebut sehingga akan menimbulkan arus induksi (Eddy Current) gambar 2.1.

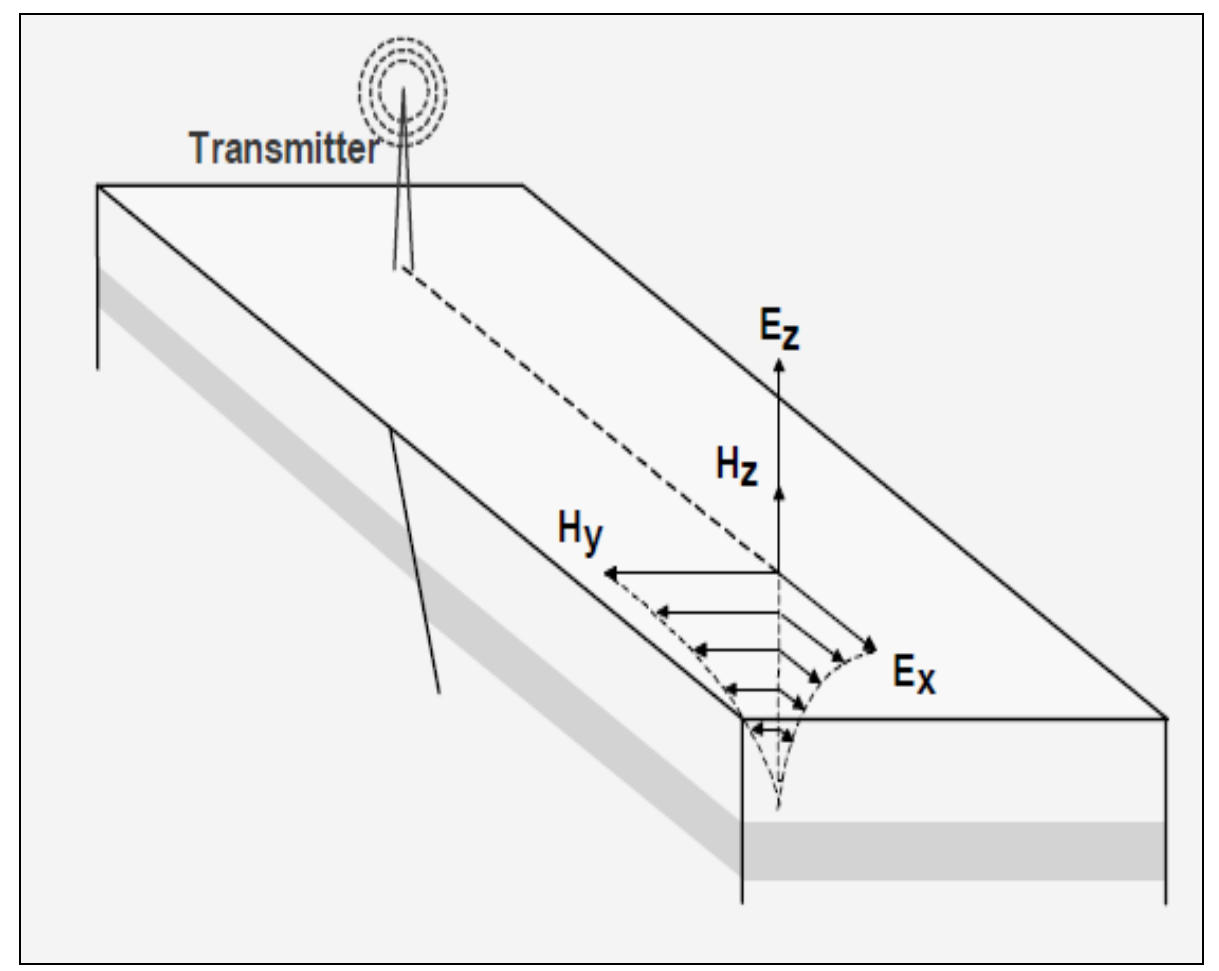

Gambar 2.1 Gelombang elektromagnetik untuk metoda VLF (Grandis, 2005) [3] 
Arus Eddy disebabkan oleh sebuah medan magnetik VLF pada bagian tanah yang lebih konduktif yang menghasilkan medan magnet sekunder dengan frekuensi yang sama dan fase yang berbeda. Bagian magnetik vertikal $\mathrm{Hz}$ berguna untuk menentukan anomali dan sebagian besar instrument VLF membandingkan medan magnetik vertikal dengan medan magnetik horizontal yang bertujuan untuk mengamati sudut tilt (Milson, 1989).

Karakteristik gelombang elektromagnetik dalam metode VLF dapat dijelaskan sebagai berikut. Pada saat gelombang primer masuk kedalam medium, gaya gerak listrik (ggl) induksi es akan muncul dengan frekuensi yang sama, tetapi fase tertinggal $90^{\circ}$ (Kaikkonen, 1979). Gambar 2.2 menunjukkan diagram vektor antara medan primer $P$ dan $\mathrm{ggl}$ induksinya. Kombinasi antara medan $P$ dan medan $S(R \cos \alpha)$ disebut komponen real (inphase) dan komponen yang tegak lurus $P$ $(R \sin \alpha)$ disebut komponen imaginer (out-ofphase, komponen kuadratur).

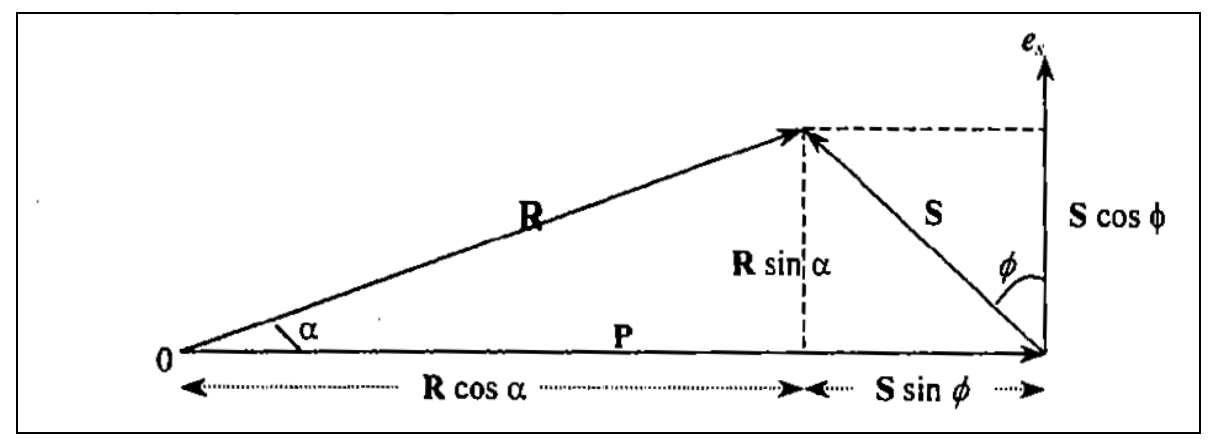

Gbr 2.2 Hubungan ampitudo dan fase gelombang sekunder (S) dan primer (P) (Kaikkonen, 1979)

Jika medan magnet horizontal adalah $\mathrm{H}_{\mathrm{x}}$ dan medan magnet vertikalnya adalah $\mathrm{H}_{\mathrm{z}}$, maka besar sudut tilt dapat ditunjukkan seperti gambar 2.3, yang besarnya adalah:

$$
\tan (2 \theta)=\frac{2\left(\frac{\mathrm{H}_{z}}{\mathrm{H}_{\mathrm{x}}}\right) \cos \emptyset}{1-\left(\frac{\mathrm{H}_{\mathrm{z}}}{\mathrm{H}_{\mathrm{x}}}\right)^{2}} \times 100 \%
$$

dan eliptisitasnya diberikan sebagai:

$$
\varepsilon=\frac{b}{a}=\frac{\mathrm{H}_{\mathrm{z}} \mathrm{H}_{\mathrm{z}} \sin \emptyset}{\left[\mathrm{H}_{\mathrm{z}} \mathrm{e}^{\mathrm{i} \emptyset} \sin \theta+\mathrm{H}_{\mathrm{x}} \cos \theta\right]^{2}} \times 100 \%
$$




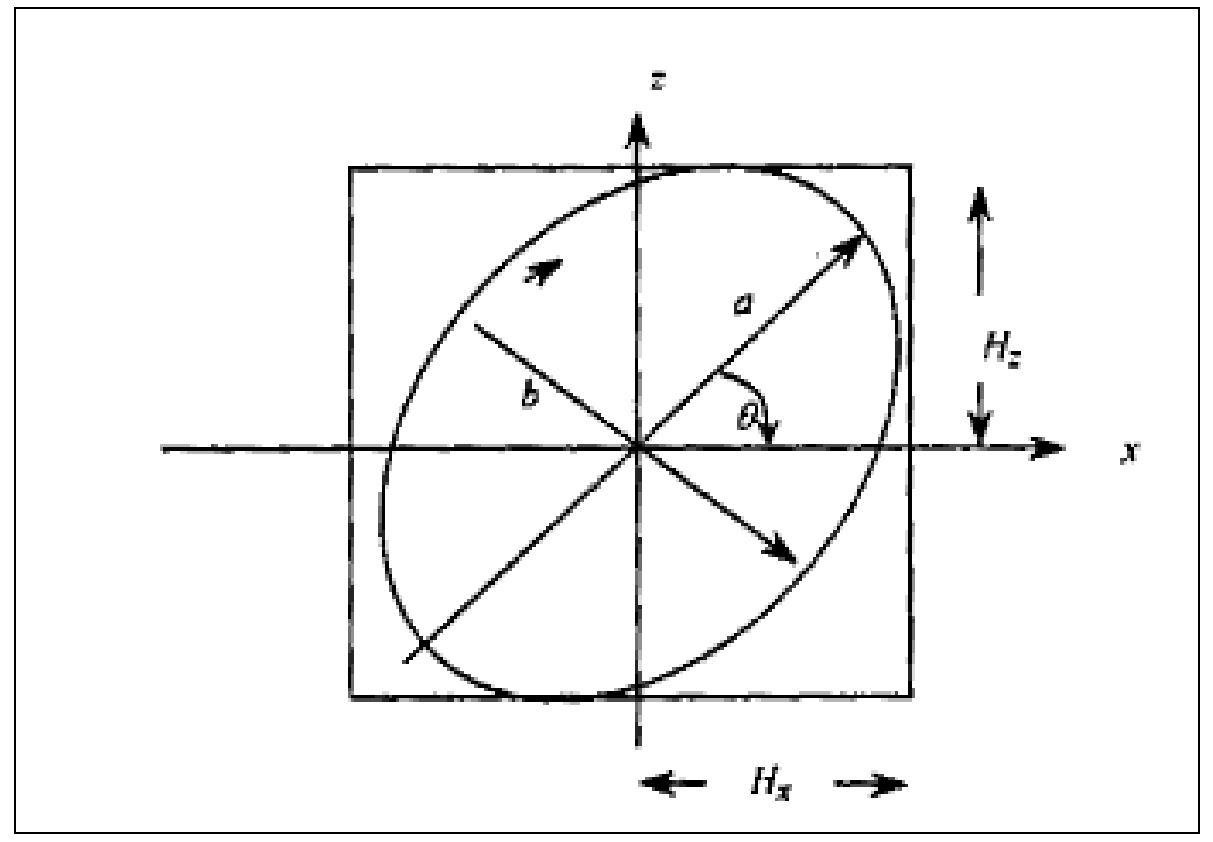

Gbr 2.3 Parameter Polarisasi Ellips

Tangen dari sudut tilt dan eliptisitas dapat digunakan untuk membandingan komponen medan magnetik sekunder $S$ vertikal dengan medan magnetik primer $P$ horizontal, serta membandingkan komponen kuadrat dari medan sekunder $S$ vertikal terhadap medan primer $P$ horizontal (Peterson dan Ronka, 1971).

\section{METODE PENELITIAN}

Tabel 3.1 Parameter akuisisi survey VLF

\begin{tabular}{|l|l|}
\hline \multicolumn{1}{|c|}{ PARAMETER } & \multicolumn{1}{c|}{ NILAI PARAMETER } \\
\hline Jumlah lintasan & 5 lintasan \\
\hline Panjang tiap lintasan & $990 \mathrm{~m}$ \\
\hline Spasi titik pengukuran & $10 \mathrm{~m}$ \\
\hline Jumlah titik pengukuran tiap lintasan & 100 titik \\
\hline Frekuensi pengukuran & $19800 \mathrm{~Hz}$ \\
\hline Data terukur & $\begin{array}{l}\text { Inphase, quadrature, tilt angle, total- } \\
\text { field }\end{array}$ \\
\hline
\end{tabular}

Beberapa peralatan utama yang di gunakan dalam penelitian ini terdiri dar satu unit T-VLF Iris yang berfungsi sebagai receiver, enam buah baterai 1.5 Volt

(pemakaian 8 jam) sebagai sumber daya untuk unit sensor dan sebuah baterai 9 Volt sebagai daya internal monitor. 
Anita, F., Purwatiningsih. 2017. Estimasi Aliran Sungai Bawah Tanah Di Daerah Dengok Dan Ngrejok Wetan Gunung Kidul, Menggunakan Metode Vlf-Em Dan Vlf-Em-Vgrad. Journal of Sainstek. 9(2): 123-130

Desain survei penelitian dengan metode Very Low Frequensi pada mode sudut tilt adalah sebagai berikut:

1. Mode sudut tilt digunakan untuk mengetahui struktur konduktifitas kontak geologi seperti zona alteri, patahan, dan dike konduktif.

2. Arah strike target memiliki sudut toleransi \pm 45 derajat dengan lokasi pemancar (gambar 3).

3. Medan primer akan memberikan fluks yang maksimum jika memotong struktur, sehingga akan memberikan kemungkinan anomali yang besar.

\section{HASIL DAN PEMBAHASAN}

Gambar 4.1 merupakan gabungan lima lintasan hasil pengolahan data sudut tilt dengan filter liniear yang dihitung pada berbagai kedalaman. Sehingga didapatkan indikasi adanya daerah konduktif dengan nilai rapat arus ekivalen yang tinggi. Kelima lintasan tersebut diukur dengan metode VLF EM yang dilakukan secara berdiri bila dikorelasikan keberadaan sungai bawah tanah, diperoleh hasil interpretasi distribusi aliran sungai bawah tanah.

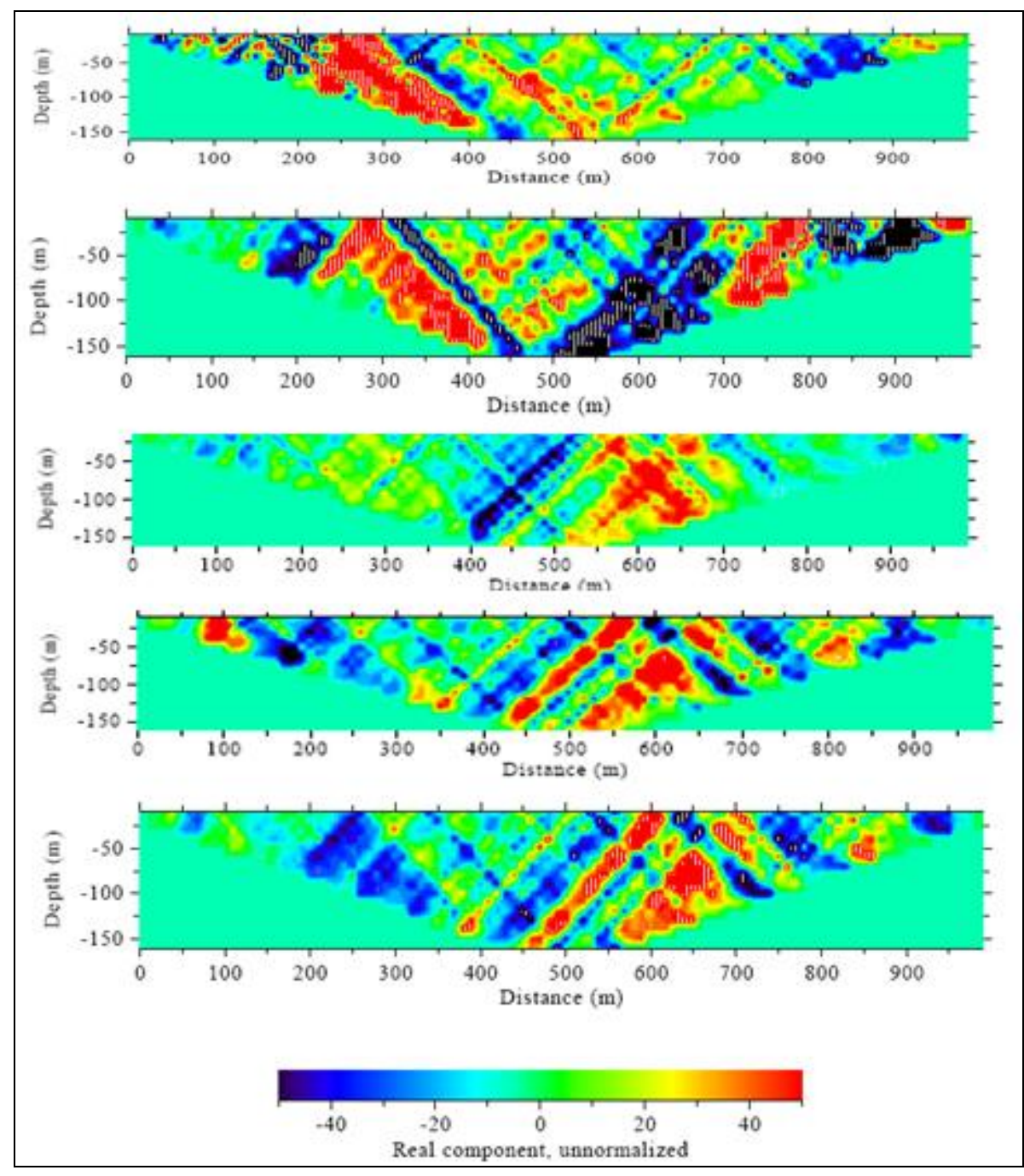

Gambar 4.1. Gambar Filter Karous Hjelt VLF-EM Gabungan 
Anita, F., Purwatiningsih. 2017. Estimasi Aliran Sungai Bawah Tanah Di Daerah Dengok Dan Ngrejok Wetan Gunung Kidul, Menggunakan Metode Vlf-Em Dan Vlf-Em-Vgrad. Journal of Sainstek. 9(2): 123-130

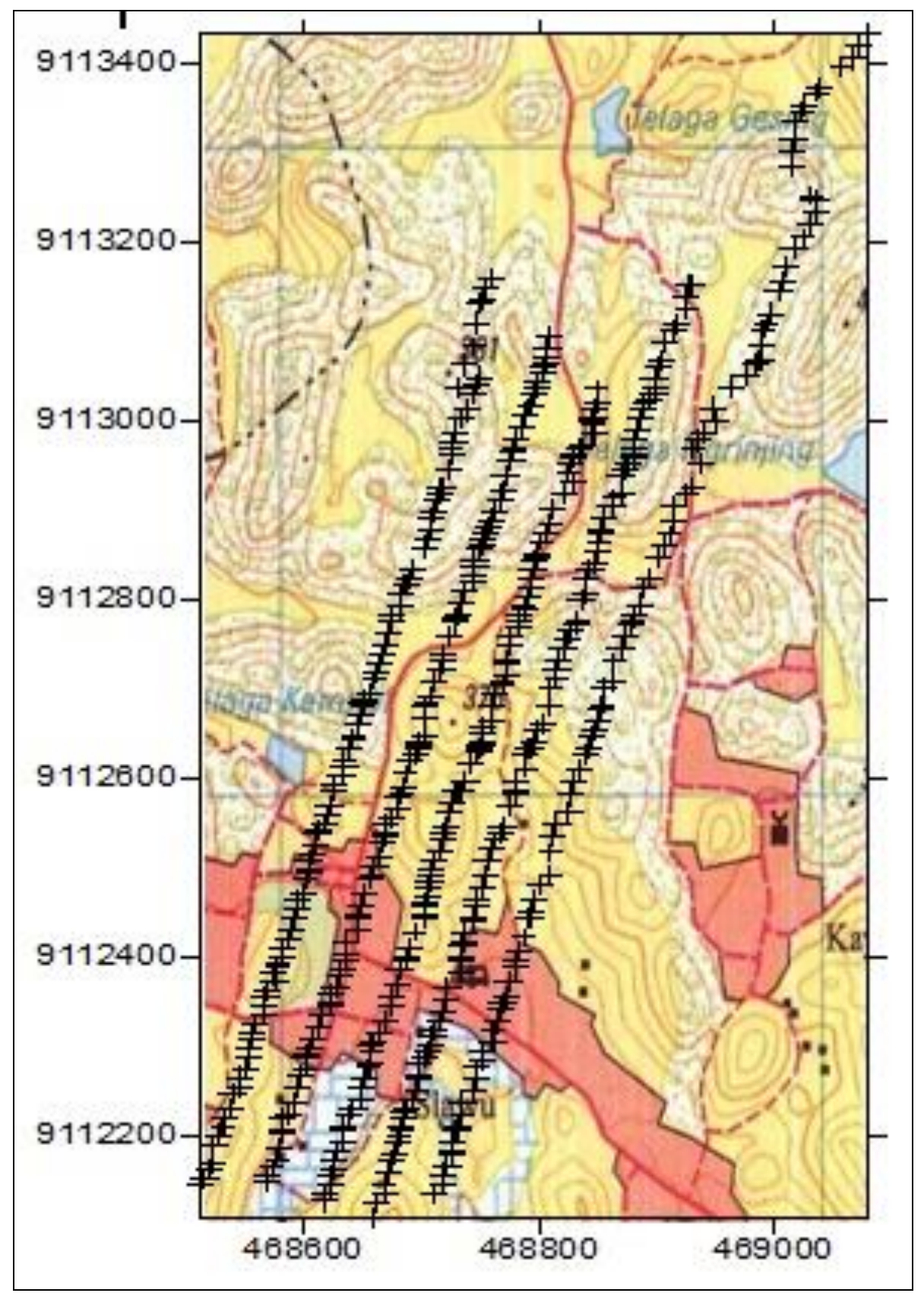

Gambar 4.2 Lokasi dan titik pengambilan data lapangan.

Gambar 4.2 merupakan gambar lintasan penelitian dari lintasan satu disebelah kiri sampai lintasan 5 disebelah kanan 
Anita, F., Purwatiningsih. 2017. Estimasi Aliran Sungai Bawah Tanah Di Daerah Dengok Dan Ngrejok Wetan Gunung Kidul, Menggunakan Metode Vlf-Em Dan Vlf-Em-Vgrad. Journal of Sainstek. 9(2): 123-130

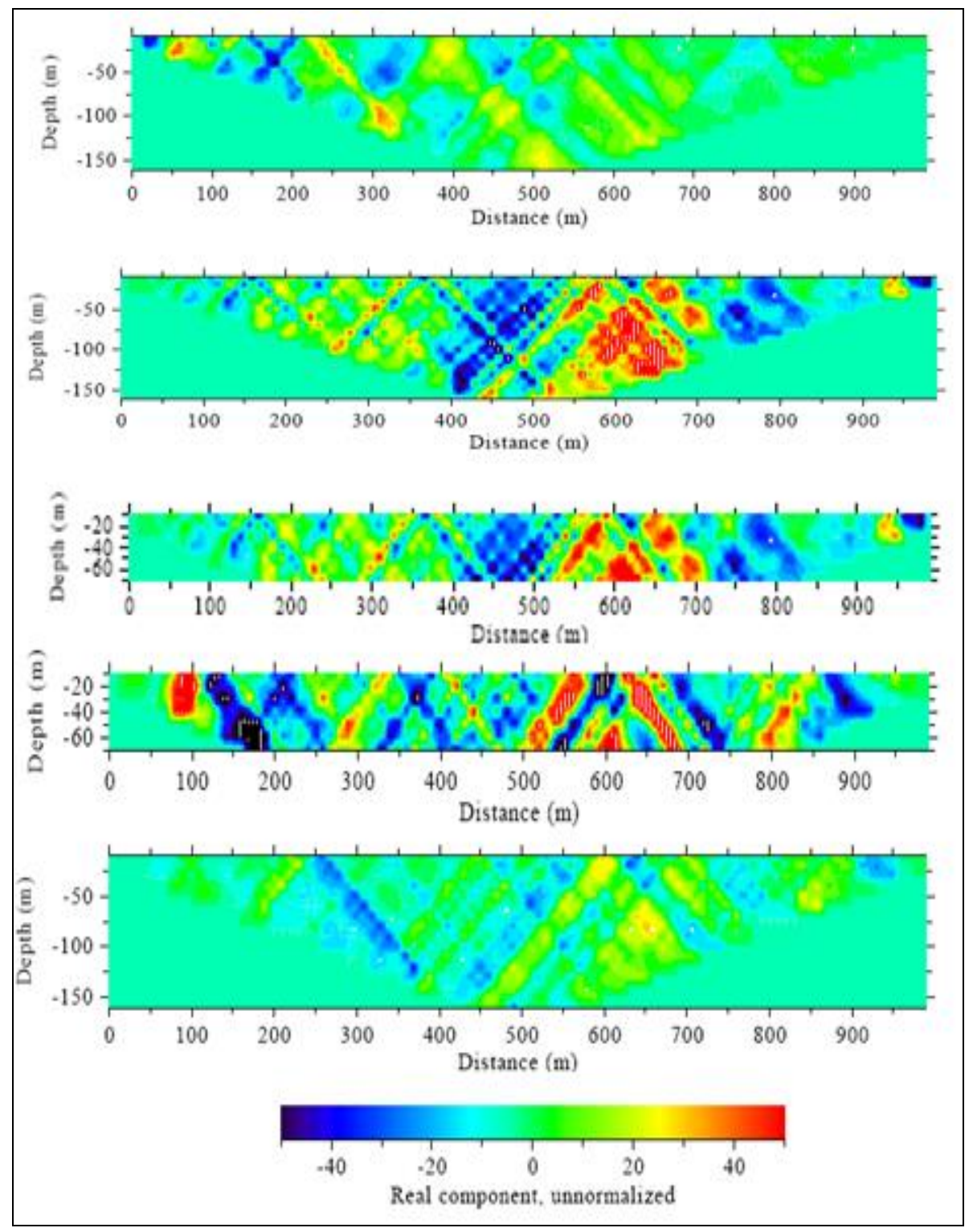

Gambar 4.3. Gambar Filter Karous Hjelt VLF-EM-VGRAD Gabungan

Gambar 4.3 merupakan gabungan lima lintasan hasil pengolahan data sudut tilt dengan filter liniear yang dihitung pada berbagai kedalaman. Sehingga didapatkan indikasi adanya daerah konduktif dengan nilai rapat arus ekivalen yang tinggi. Kelima lintasan tersebut diukur dengan metode VLF EM-VGRAD yang dilakukan secara berdiri bila dikorelasikan keberadaan sungai bawah tanah, diperoleh hasil interpretasi distribusi aliran sungai bawah tanah.

\section{KESIMPULAN}

Dari hasil penelitian estimasi aliran sungai bawah tanah di desa pucanganom kabupaten gunung kidul menggunakan VLF- 
EM dan VLF-EM-vGRAD, dapat disimpulan bahwa:

1. Terdapat respon nilai resistivitas bawah permukaan., hal ini menandakan bahwa di lokasi penelitian ini terdapat aliran bawah permukaan.

2. Dari dua metode yang digunakan, metode yang paling efektif adalah dengan VLF EM, hal ini dapat dilihat dari hasil filter Karous Hjelt yang memperlihatkan kekontrasan resistivitas pada vlf em dibandingkan dengan VLF-EM-Vgrad

\section{DAFTAR KEPUSTAKAAN}

Grandis H. 2005. Aplikasi Metoda VLF-EM Untuk Studi Geofisika Dekat-Permukaan, Catatan Kuliah, Departemen Geofisika ITB, Bandung.

Kusumayudha SB. 2005. Hidrogeologi Karst dan Geometri Fraktal di Daerah Gunungsewu, Adicita, Yogyakarta.

Kaikkonen P. 1979. Numerical VLF Modelling, Geophysical Prospecting, 27, 815-834.
Milson J. 1989. Field Geophysics, John Wiley\&Son, London.

Peterson NR and Ronka V. 1971. Five Years of Surveying With The Very Low Frequency-Elektromagnetik Method, Geoexploration, 9, 7-26.

Santos FAM, Almeida EP, Gomes M dan Pina A. 2006a. Hydrogeological Investigation In Santiago Island (Cabo Verde) Using Magnetotellurics And VLF Methods, Journal of African Earth Sciences 45, 421-430.

Santos FAM, Mateus A, Figueiras J dan Gonçalves MA. 2006b. Mapping Groundwater Contamination Around A Landfill Facility Using The VLF-EM Method - A Case Study, Journal of Applied Geophysics xx .

Sismanto, Eddy H, Sudarmadji, M. Nukman, dan W. Suryanto. 2003. Tanggapan Gelombang Elektromagnetik Frekuensi Rendah (VLF) dari Sungai Bawah Tanah: Sebuah Uji Coba Metoda VLF di Sekitar Goa Bribin, Gunungkidul, Yogyakarta, Jurnal Fisika Indonesia, No.2, Vol.VII, Edisi April 2003, 31-42. 